\title{
The risk and prognosis of cancer after hospitalisation for herpes zoster: a population-based follow-up study
}

\author{
HT Sørensen*,', JH Olsen², P Jepsen', SP Johnsen', HC Schønheyder ${ }^{3}$ and L Mellemkjær ${ }^{2}$ \\ 'Department of Clinical Epidemiology, Aarhus University Hospital, Vennelyst Boulevard 6, Building 260, 8000 Aarhus C, Denmark; ${ }^{2}$ Institute of Cancer \\ Epidemiology, The Danish Cancer Society, Strandboulevarden 49, 2100 Copenhagen $\varnothing$, Denmark; ${ }^{3}$ Department of Clinical Microbiology, Aalborg \\ Hospital, 9100 Aalborg, Denmark
}

We examined the risk of cancer and survival in a cohort of patients hospitalised with herpes zoster between 1977 and 1996, drawn from the Danish National Registry of Patients. Through linkage with the Danish Cancer Registry, we compared the observed number of cancers with the expected number on the basis of national age-, gender-, and site-specific incidence rates. The survival of herpes zoster patients with cancer was compared with that of non-herpes zoster patients with cancer. Among the 10588 patients hospitalised with herpes zoster whom we identified, 1427 cancers were observed compared with 1239 expected (relative risk = I.2, 95\% confidence interval I.I-1.2). The risk was substantially elevated during the first year of follow-up, mainly for haematological cancer. Patients with cancer within I year of follow-up had a higher prevalence of distant metastases than controls, although the mortality was similar. For those with haematological cancer, however, the mortality was higher for herpes zoster patients than for controls. Haematological cancer following hospitalisation for herpes zoster has a poorer prognosis than in non-herpes zoster patients. British Journal of Cancer (2004) 91, 1275- 1279. doi:I0.1038/sj.bjc.6602 I 20 www.bjcancer.com

Published online 24 August 2004

(c) 2004 Cancer Research UK

Keywords: herpes zoster; risk; incidence; survival; prognosis; epidemiology

Herpes zoster occurs frequently in immunocompromised patients, such as the elderly and those with lymphoproliferative malignancies, AIDS, and in transplant recipients (Dolin et al, 1978; Mazur and Dolin, 1978; Freidman-Kien et al, 1986; Melbye et al, 1987; Donahue et al, 1995; Poulsen et al, 1996; Gnann and Richard, 2002). An association between cancer and herpes zoster has been recognised since 1955 (Wyburn-Mason, 1955), and it has been hypothesised that herpes zoster may be a predictor of a subsequent diagnosis of cancer (Smith and Fenske, 1995). Case reports have suggested such an association (Wright and Winer, 1961; Muller, 1967; Cohen et al, 1984), but only three relatively small studies have prospectively examined the risk of malignancy subsequent to herpes zoster, and these found no significantly increased risk (Ragozzino et al, 1982; Fueyo and Lookingbill, 1984; Wurzel et al, 1986). Other studies have examined this association, but most of them were based on patients with prevalent cancer, did not include controls, or were unable to disentangle the temporal relationship (Wyburn-Mason, 1955; McGregor, 1957; de Moragas and Kierland, 1957; Wright and Winer, 1961; Merselis et al, 1963; Muller, 1967; Rogers and Tindall, 1971; Schimpff et al, 1972; Brown, 1976). In addition, little is known about the prognosis of patients with cancer discovered after hospitalisation with herpes zoster.

To assess the herpes zoster-cancer association without such limitations, we determined the risk of cancer after hospitalisation for herpes zoster, as well as the prognosis of such cancers, using nationwide population-based data from the Danish Registry of Patients and the Danish Cancer Registry.

*Correspondence: Professor HT Sørensen; E-mail: hts@soci.au.dk Received 5 April 2004; revised 5 July 2004; accepted 7 July 2004; published online 24 August 2004

\section{METHODS}

The Danish National Registry of Patients was established in 1977, and $99.4 \%$ of all discharges from Danish nonpsychiatric hospital departments are recorded there (Andersen et al, 1999). Recorded information includes the civil registration number, the dates of admission and discharge, the surgical procedures performed, and up to 20 discharge diagnoses. The National Health Service provides tax-supported free medical care to all Danish citizens. The civil registration number, which is unique to every Danish citizen, permits accurate linkage of information among registers. Discharge diagnoses were coded according to the Danish version of the International Classification of Diseases, 8th revision (ICD-8), until 31 December 1993, and according to the 10th revision thereafter (Andersen et al, 1999).

All hospitalisations for herpes zoster (ICD-8 codes 053.00053.9 and ICD-10 codes B02.0-B02.9) from 1 January 1977 to 31 December 1996 were extracted from the National Registry of Patients. We identified 13414 patients hospitalised with herpes zoster and obtained their full hospitalisation history. This led to the exclusion of 402 patients who had received an organ transplantation before the diagnosis of herpes zoster or were diagnosed with human immunodeficiency virus at any time during the study period, and 2026 patients with a cancer diagnosis prior to or within 2 months after the diagnosis of herpes zoster.

The remaining 10986 herpes zoster patients were linked to the Central Population Registry for verification of the civil registration number and for information on vital status and emigration. This led to the exclusion of 398 patients who died during the hospitalisation for herpes zoster or had an erroneous registration. The resulting 10588 eligible herpes zoster patients were classified 
in two ways on the basis of ICD codes: (1) into 7434 patients with uncomplicated herpes zoster and 3154 patients with complicated herpes zoster; and (2) into 392 patients with disseminated herpes zoster and 10196 patients with localised herpes zoster.

The 10588 herpes zoster patients were followed for cancer occurrence from 2 months after the date of discharge with a first time diagnosis of herpes zoster to be certain that the zoster diagnosis came before the cancer diagnosis until (1) the date of death or emigration, identified through the Central Population Registry, (2) a diagnosis of organ transplantation or primary immune deficiency, identified through the National Registry of Patients, or (3) until 31 December 1998, whichever came first.

Information on cancer occurrence was obtained through record linkage to the Danish Cancer Registry with records of all incident cases of cancer in Denmark since 1943. Cancers are classified according to the modified Danish version of the International Classification of Diseases, 7th revision (Storm et al, 1997). The registration is based on notification forms that are completed by hospital departments (including departments of pathology and forensic medicine) and practicing physicians whenever a case of cancer is diagnosed or found at autopsy, and whenever changes to the initial diagnosis are made. The cases thus reported manually are supplemented by cases revealed by the computerised linkages to the death certificate file and the National Registry of Patients. Ambiguous or contradictory information, either within a notification form or between forms, leads to requests for clarification in approximately $10 \%$ of notifications received. Comprehensive validation has shown that the Registry is $95-98 \%$ complete and valid (Andersen et al, 1999).

Through the Cancer Registry, we aimed to identify a control group of up to 10 cancer patients without herpes zoster for each herpes zoster patient with cancer. Controls were matched on cancer type, gender, age in 10-year age groups, and calendar year of diagnosis in 5-year periods. However, we were unable to identify 10 matching patients for each herpes zoster patient with cancer, so the control group comprised only 12193 patients.

\section{Statistical analysis}

The expected number of cancers was calculated on the basis of Danish national incidence rates for primary cancers according to gender, age, and calendar time in 5-year intervals. Multiplying the number of person-years under observation by the appropriate cancer incidence rates yielded the number of cancers that would be expected if patients with herpes zoster had the same risk of cancer as that of the general population. Confidence intervals (CIs) for the standardised incidence ratio - that is, the relative risk, calculated as the ratio of observed to expected cancers - were based on the assumption that the observed number of cases in a specific category follows a Poisson distribution. We examined the association between herpes zoster and all cancer types combined, as well as the association between herpes zoster and haematological cancers, cancers associated with immunosuppression (Nasca, 2001), and other cancers.

Through the Danish Cancer Registry, we obtained information on the extent of cancer spread among the herpes zoster patients who developed cancer during follow-up (cases). The extent of spread was divided into 'no spread,' 'regional spread', and 'distant metastases'. We calculated the prevalence ratio of distant metastases (the proportion of cases with distant metastases divided by the proportion of controls with distant metastases) and an associated $95 \%$ CI.

We used proportional hazards regression analyses to compare the risk of death after a cancer diagnosis for cases relative to that for controls. We did separate analyses on cases with haematological cancer and those with other types of cancer. The comparisons were based on estimation of mortality ratios and associated $95 \%$
CI. All statistical analyses were performed with Stata software (Stata Corporation, Texas, USA).

\section{RESULTS}

The 10588 herpes zoster patients in the study (3972 men and 6616 women), were followed for 75774 person-years yielding an average length of follow-up of 7.2 years. The median age at first hospitalisation for herpes zoster was 72 years.

\section{Cancer risk}

We found a total of 1427 cases of cancer with 1239 expected, yielding an overall relative risk of 1.2 . (95\% CI 1.1-1.2). The relative risks were the same in men and women (data not shown), and did not depend on the year of herpes zoster diagnosis (data not shown).

In the first year of follow-up, 188 cancers were identified, yielding a cumulative cancer risk of $1.8 \%$. Of the 188 cancers, 29 $(15 \%)$ were haematological cancers, yielding a cumulative risk of haematological cancer of $0.3 \%$. The overall relative risk of a diagnosis of cancer during the first year of follow-up was 1.3 (95\% CI $1.1-1.5$ ) and did not vary with the year of hospitalisation. In the first year of follow-up, we found a particularly high risk for haematological cancer with a relative risk of 3.4 (95\% CI $2.3-4.9)$ (Table 1).

The relative risk of haematological cancer (Hodgkin's disease, non-Hodgkin's lymphoma, multiple myeloma, and leukaemia) varied with time of follow-up after the herpes zoster diagnosis (Tables 1 and 2), so that it was 4.0 (95\% CI 1.3-9.3) in the first 3 months, 3.2 (95\% CI 1.4-6.4) between 3 and 6 months, 4.6 (95\% CI $2.3-8.2$ ) between 6 and 9 months, 2.1 (95\% CI $0.7-4.9$ ) between 9

Table I Relative risk (RR) for selected cancers within the first year of follow-up among patients previously hospitalised for herpes zoster; followup started 2 months after the date of discharge with herpes zoster

\begin{tabular}{|c|c|c|c|}
\hline & Observed & $\mathbf{R R}$ & $95 \% \mathrm{Cl}^{\mathrm{a}}$ \\
\hline All malignant neoplasms & 188 & 1.3 & $1.1-1.5$ \\
\hline Haematological cancers & 29 & 3.4 & $2.3-4.9$ \\
\hline Non-Hodgkin's lymphomab & 11 & 3.8 & $1.9-6.7$ \\
\hline Hodgkin's lymphoma & 0 & - & - \\
\hline Multiple myeloma & 8 & 4.8 & $2.1-9.4$ \\
\hline Leukaemia & 10 & 2.8 & $1.3-5.1$ \\
\hline Immune-related cancers & 32 & 1.1 & $0.8-1.6$ \\
\hline Liver & 3 & 1.5 & $0.4-6.0$ \\
\hline Cervix & I & 0.5 & $0.01-2.5$ \\
\hline Nonmelanoma skin cancer & 24 & 1.1 & $0.7-1.7$ \\
\hline Malignant melanoma & । & 0.5 & $0.01-2.5$ \\
\hline Sarcoma & 3 & 2.7 & $0.6-7.8$ \\
\hline All other sites ${ }^{d}$ & 127 & 1.2 & $1.0-1.4$ \\
\hline Brain & 0 & - & - \\
\hline Oesophagus & 2 & 1.3 & $0.2-5.4$ \\
\hline Stomach & 6 & 1.1 & $0.4-2.3$ \\
\hline Colon & 12 & 0.8 & $0.4-1.4$ \\
\hline Rectum & 7 & 1.0 & $0.4-2.0$ \\
\hline Pancreas & 6 & 1.3 & $0.5-2.7$ \\
\hline Lung & 22 & 1.4 & $0.9-2.2$ \\
\hline Breast & 12 & 0.8 & $0.4-1.4$ \\
\hline Corpus uteri & 3 & 0.9 & $0.2-2.6$ \\
\hline Ovary & 7 & 2.3 & $0.9-4.8$ \\
\hline Prostate & 14 & 1.4 & $0.8-2.4$ \\
\hline Kidney & 6 & 1.7 & $0.6-3.8$ \\
\hline Bladder & 12 & 1.4 & $0.8-2.5$ \\
\hline
\end{tabular}

${ }^{a} \mathrm{Cl}$ denotes confidence interval. ${ }^{b}$ Non-Hodgkin's lymphoma is also classified as an immune-related cancer. 'Among sarcomas, only Kaposi's sarcoma is regarded as an immune-related cancer. ${ }^{\mathrm{d}}$ Only selected sites are specified. 
Table 2 Relative risk (RR) for selected cancers beyond the first year of follow-up among patients previously hospitalised for herpes zoster; followup started 2 months after the date of discharge with herpes zoster

\begin{tabular}{|c|c|c|c|}
\hline & Observed & $\mathbf{R R}$ & $95 \% \mathrm{Cl}^{\mathrm{a}}$ \\
\hline All malignant neoplasms & 1239 & 1.1 & $1.1-1.2$ \\
\hline Haematological cancers & II & 1.7 & $1.4-2.0$ \\
\hline Non-Hodgkin's lymphomab & 38 & 1.6 & $1.1-2.2$ \\
\hline Hodgkin's lymphoma & 6 & 3.0 & $1.1-6.6$ \\
\hline Multiple myeloma & 22 & 1.7 & $1.1-2.6$ \\
\hline Leukaemia & 45 & 1.7 & $1.2-2.2$ \\
\hline Immune-related cancers & 251 & 1.1 & $1.0-1.2$ \\
\hline Liver & 13 & 1.3 & $0.7-2.2$ \\
\hline Cervix & 11 & 0.8 & $0.4-1.5$ \\
\hline Nonmelanoma skin cancer & 203 & 1.1 & $1.0-1.3$ \\
\hline Malignant melanoma & 15 & 0.8 & $0.5-1.3$ \\
\hline Sarcoma ${ }^{c}$ & 9 & I.I & $0.5-2.1$ \\
\hline All other sites ${ }^{d}$ & 877 & 1.1 & $1.0-1.2$ \\
\hline Brain & 29 & 1.6 & $1.1-2.3$ \\
\hline Oesophagus & 16 & 1.5 & $0.9-2.4$ \\
\hline Stomach & 44 & 1.3 & $0.9-1.7$ \\
\hline Colon & 97 & 0.9 & $0.7-1.1$ \\
\hline Rectum & 48 & 0.9 & $0.7-1.2$ \\
\hline Pancreas & 39 & 1.2 & $0.8-1.6$ \\
\hline Lung & 130 & 1.2 & $1.0-1.4$ \\
\hline Breast & 127 & 1.1 & $0.9-1.3$ \\
\hline Corpus uteri & 24 & 1.0 & $0.6-1.4$ \\
\hline Ovary & 23 & 1.1 & $0.7-1.6$ \\
\hline Prostate & 79 & 1.2 & $0.9-1.4$ \\
\hline Kidney & 32 & 1.3 & $0.9-1.8$ \\
\hline Bladder & 59 & 1.0 & $0.7-1.2$ \\
\hline
\end{tabular}

${ }^{a} \mathrm{Cl}$ denotes confidence interval. ${ }^{b}$ Non-Hodgkin's lymphoma is also classified as an immune-related cancer. 'Among sarcomas, only Kaposi's sarcoma is regarded as an immune-related cancer. ${ }^{\mathrm{d}}$ Only selected sites are specified.

months and 1 year, 1.9 (95\% CI $1.5-2.5)$ between 1 and 5 years, 1.3 (95\% CI $0.9-1.9)$ between 5 and 10 years, and 1.7 (95\% CI $1.1-2.6$ ) after more than 10 years. The relative risks of nonhaematological cancer in the same periods were 1.7 (95\% CI $1.2-2.4), 1.5$ (95\% CI $1.1-1.9), 0.9$ (95\% CI $0.6-1.3), 0.8$ (95\% CI $0.5-1.1), 1.1$ (95\% CI $1.0-1.2), 1.1$ (95\% CI $1.0-1.2)$, and 1.1 (95\% CI $1.0-1.3)$, respectively.

For patients with uncomplicated herpes zoster, the relative risk of any cancer during the first year of follow-up was 1.4 (95\% CI $1.2-1.6)$, whereas it was $1.1(95 \%$ CI $0.8-1.5)$ for patients with complicated herpes zoster. For patients with disseminated herpes zoster, it was 1.5 (95\% CI 0.7-2.8), and it was 1.3 (95\% CI 1.1-1.5) for patients with other localised herpes zoster.

\section{Cancer extent and prognosis}

Because we were unable to identify matching patients for all 1382 herpes zoster patients with cancer, only 1341 (97\%) of these patients were included in the analyses of extent of cancer and of

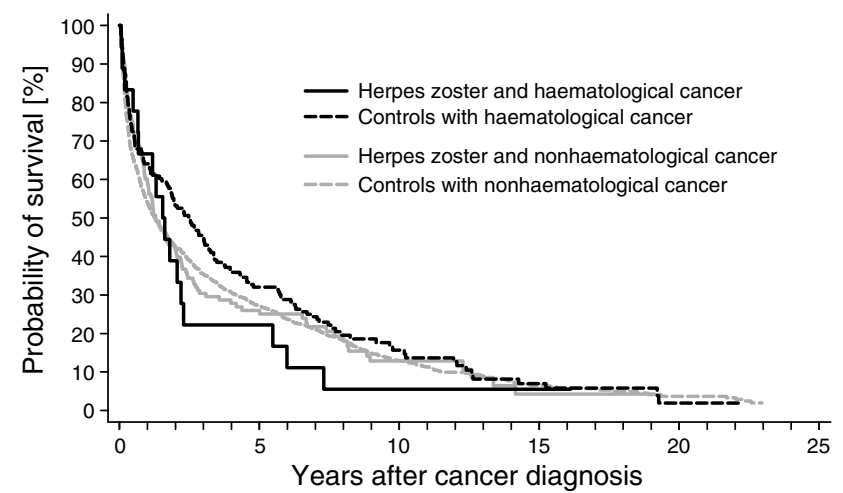

Figure I Survival curves for patients with herpes zoster (solid lines) and haematological cancer (black) or nonhaematological cancer (grey). Cancers were diagnosed within the first year of follow-up. Follow-up started 2 months after the date of discharge with herpes zoster. Matched controls are represented by dashed lines.

survival after the cancer diagnosis. We had information on the extent of cancer at the time of diagnosis in $79 \%$ of cases and $81 \%$ of controls. Among those cases who developed cancer within the first year after hospitalisation for herpes zoster, the prevalence ratio of distant spread was higher among the herpes zoster patients than among the controls (prevalence ratio 1.27; 95\% CI 0.99-1.63), whereas it was close to unity among those who developed cancer more than 1 year after hospitalisation for herpes zoster (prevalence ratio 1.07; 95\% CI $0.92-1.23$ ) (Table 3 ).

The survival curves for herpes zoster patients in whom cancer was diagnosed within the first year after herpes zoster hospitalisation, and their matched controls, were almost similar with a mortality ratio of $1.02(95 \%$ CI $0.85-1.22)$. For cases with haematological cancer, however, the mortality ratio was 1.38 (95\% CI $0.83-2.28)$, whereas that for cases with nonhaematological cancer was 0.98 (95\% CI 0.84-1.19) (Figure 1).

The survival curve for herpes zoster patients in whom cancer was diagnosed more than 1 year after the herpes zoster hospitalisation was similar to that for their matched controls. The mortality ratio was 1.03 (95\% CI 0.96-1.11). For cases with haematological cancer, the survival curves for cases and their controls were only slightly different with a mortality ratio of 1.11 (95\% CI $0.85-1.46)$, and for cases with nonhaematological cancer, the mortality ratio was 1.02 (95\% CI $0.95-1.11)$.

\section{DISCUSSION}

In this large, population-based, follow-up study, we found an increased risk of several types of cancer after hospitalisation for herpes zoster, particularly during the first year of follow-up. In particular, there was a strong association between herpes zoster and haematological cancers. Hospitalisation for herpes zoster was

Table 3 Extent of the spread of cancer according to the presence or absence of herpes zoster

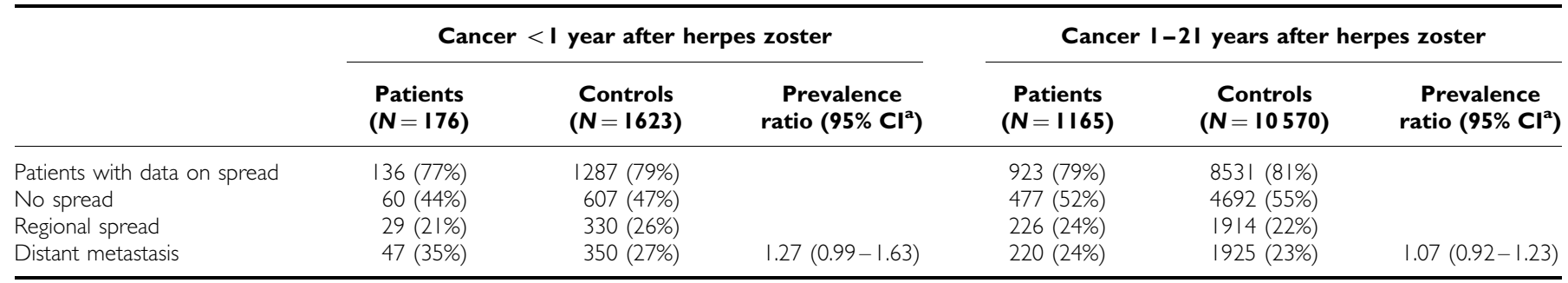

${ }^{\mathrm{a}} \mathrm{Cl}$ denotes confidence interval. 
also a marker of long-term cancer risk - even after 10 years, we found a 1.7-fold increase in the risk of haematological cancer. Further, patients with herpes zoster were more likely to have advanced cancer than matched controls, although survival curves for nonhaematological cancer were similar. For haematological cancer, however, herpes zoster patients had a poorer survival than their matched controls.

Our findings differ from those of the few previous studies on this topic (Ragozzino et al, 1982; Fueyo and Lookingbill, 1984, Wurzel et al, 1986). In aggregate, three small studies followed 662 patients. A total of 91 cancer cases were observed compared with 84 expected in the two studies with internal or external controls (Ragozzino et al, 1982; Fueyo and Lookingbill, 1984). No cancer cases were found in the third study of children (Wurzel et al, 1986). Consequently, these studies had neither the power to detect a substantially increased overall cancer risk nor the ability to study site-specific cancer risks. In addition, they had few clinical details.

There may be several reasons as to why cancer might be associated with herpes zoster. Increased diagnostic effort could explain the association in the short term, but it seems unlikely for heightened surveillance to explain an increased risk many years after the hospitalisation for herpes zoster. Moreover, there was no compensating deficit after a time-limited period of increased risk, and the risk differed between haematological and nonhaematological cancers.

Confounding by smoking may explain a part of the increased risk in the long term since we found an increased risk of many tobacco-related cancers, and smoking, in itself, has some impact on the immune function (Holt, 1987). One common risk factor for both herpes zoster and cancer is cell-mediated immunity, which likely explains the strong associations with haematological cancers. Varicella zoster virus remains in a dormant state until the cellmediated immune system is depressed and allows the virus to multiply. There is some evidence that infections may promote certain types of cancers (Kuper et al, 2000). It has also been suggested that herpes zoster has a direct carcinogenic effect (Rogers and Tindall, 1971).

We found an increased long-term risk of brain tumour after herpes zoster hospitalisation, but it is not possible to assess whether this finding was caused by chance or unknown confounding, or whether it reflects the tropism for the virus towards neural tissue. However, this hypothesis was not supported by the findings of an American case-control study in which adults with glioma were less likely than controls to have had prior varicella zoster virus infection or to have an immunoglobulin-G antibody response adequate to indicate positivity (Wrensch et al, 1997, 2001).

\section{REFERENCES}

Andersen TF, Madsen M, Jørgensen J, Mellemkjær L, Olsen JH (1999) The Danish National Hospital Register. A valuable source of data for modern health sciences. Dan Med Bull 46: 263-268

Brown GR (1976) Herpes zoster: correlation of age, sex, distribution, neuralgia, and associated disorders. South Med J 69: 576-578

Cohen N, Weissgarten J, Pik A, Modai D (1984) Disseminated herpes zoster and hypernephroma: chance incidence or first reported case? Isr J Med Sci 20: $547-548$

de Moragas JM, Kierland RR (1957) The outcome of patients with herpes zoster. Arch Dermatol 75: 193-196

Dolin R, Reichman RC, Mazur MH, Whitley RJ (1978) Herpes zostervaricella infection in immunocompromised patients. Ann Intern Med 89: $375-388$

Donahue JG, Choo PW, Manson JE, Platt R (1995) The incidence of herpes zoster. Arch Intern Med 155: 1605-1609

Freidman-Kien AE, Lafleur FL, Gendler E, Hennessey NP, Montagna R, Halbert S, Rubinstein P, Krasinski K, Zang E, Poiesz B (1986) Herpes
The survival curves for herpes zoster patients with nonhaematological cancer and controls were similar indicating that herpes zoster is not associated with particularly aggressive nonhaematological cancer. For haematological cancer, on the other hand, herpes zoster appears to be associated with more aggressive disease, and this is similar to what has been found for other paraneoplastic syndromes, for example, venous thromboembolism and hypercalcaemia (Kristensen et al, 1998; Sørensen et al, 2000).

The study population was large and well defined, and the longterm follow-up was complete, since our design used computerised registries with complete nationwide coverage of hospitalised patients. Consequently, our findings are limited to a population of severe herpes zoster cases that require hospitalisation, but the risk estimates varied only slightly with the type of herpes zoster patients. Limitations of our study are the existence of coding errors and the possible misclassification of the herpes zoster diagnosis in the National Registry of Patients. If nondifferential, this problem would reduce the strength of the associations we reported. Also, we lacked direct information on potential confounders, such as cigarette smoking and use of immunosuppressive drugs.

Our data clearly showed an association between hospitalisation for herpes zoster and cancer, in contrast to previous research, and even demonstrated a long-term association. Our data are consistent with the hypothesis that herpes zoster may be a marker of haematological cancers, in particular. Nonetheless, the limitations of our data prevent us from suggesting guidelines for searching for occult cancer in patients with herpes zoster. In our cohort, patients diagnosed with cancer in the first 2 months after herpes zoster were excluded, but it is most likely that some cancers diagnosed in the following months were present at the time of hospitalisation for herpes zoster. Early diagnosis of some cancers would have required extensive work-up, and it is unclear whether early diagnosis would have changed the outcome. Some of the haematological cancers might be detected by simple methods, but only $1.8 \%$ of herpes zoster patients had a cancer diagnosis within the first year of follow-up, including $0.3 \%$ with haematological cancer, and $35 \%$ had metastases at the time of diagnosis. These findings suggest that cancer screening of patients hospitalised for herpes zoster will have low efficacy.

\section{ACKNOWLEDGEMENTS}

The study was supported by the Danish Cancer Society, the Oncological Research Unit at Aalborg Hospital, and Leo and Ingeborg Dannin Foundation for Scientific Research. zoster: a possible early clinical sign for development of acquired immunodeficiency syndrome in high-risk individuals. $J$ Am Acad Dermatol 14: 1023 - 1028

Fueyo MA, Lookingbill DP (1984) Herpes zoster and occult malignancy. J Am Acad Dermatol 11: 480-482

Gnann JW, Richard WJ (2002) Herpes zoster. N Engl J Med 347: 340-346 Holt PG (1987) Immune and inflammatory function in cigarette smokers. Thorax 42: $241-249$

Kristensen B, Ejlertsen B, Mouridsen HT, Loft H (1998) Survival in breast cancer patients after the first episode of hypercalcaemia. J Intern Med 244: $189-198$

Kuper H, Adami HO, Trichopoulos D (2000) Infections as a major preventable cause of human cancer. J Intern Med 248: 171-183

Mazur MH, Dolin R (1978) Herpes zoster at the NIH: a 20 year experience. Am J Med 65: 738-744

McGregor RM (1957) Herpes zoster, chicken-pox, and cancer in general practice. BMJ 32: $84-87$ 
Melbye M, Grossman RJ, Goedert JJ, Eyster ME, Biggar RJ (1987) Risk of AIDS after herpes zoster. Lancet 1: 728-731

Merselis JG, Kaye D, Hook EW (1963) Disseminated herpes zoster. Arch Intern Med 113: 679-686

Muller SA (1967) Association of zoster and malignant disorders in children. Arch Dermatol 96: 657-664

Nasca PC (2001) Immunity and cancer risk. In Fundamentals of Cancer Epidemiology Nasca PC, Pestides H (eds) Gaithersburg, NY: Aspen Publishers, pp 255-273

Poulsen A, Schmiegelow K, Yssing M (1996) Varicella zoster infections in children with acute lymphoblastic leukemia. Pediatr Hematol Oncol 13: $231-238$

Ragozzino MW, Melton LJ, Kurland LT, Chu CP, Perry HO (1982) Risk of cancer after herpes zoster: a population-based study. $N$ Engl J Med 307: $393-397$

Rogers RS, Tindall JP (1971) Geriatric herpes zoster. J Am Geriatr Soc 19: 495-504

Schimpff S, Serpick A, Stoler B, Rumack B, Mellin H, Joseph JM, Block J (1972) Varicella-Zoster infection in patients with cancer. Ann Intern Med 76: $241-254$
Smith JB, Fenske NA (1995) Herpes zoster and internal malignancy. South Med J 88: 1089-1092

Sørensen HT, Mellemkjær L, Olsen JH, Baron JA (2000) Prognosis of cancers associated with venous thromboembolism. $N$ Engl J Med 343: $1846-1850$

Storm HH, Michelsen EV, Clemmensen IH, Pihl J (1997) The Danish Cancer Registry - history, content, quality and use. Dan Med Bull 44: $535-539$

Wrensch M, Weinberg A, Wiencke J, Masters H, Miike R, Barger G, Lee M (1997) Does prior infection with varicella-zoster virus influence risk of adult glioma? Am J Epidemiol 145: 594-597

Wrensch M, Weinberg A, Wiencke J, Miike R, Barger G, Kelsey K (2001) Prevalence of antibodies to four herpesviruses among adults with glioma and controls. Am J Epidemiol 154: $161-165$

Wright ET, Winer LH (1961) Herpes zoster and malignancy. Arch Dermatol 84: $242-244$

Wurzel CL, Kahan J, Heitler M, Rubin LG (1986) Prognosis of herpes zoster in healthy children. Am J Dis Child 140: 477-478

Wyburn-Mason R (1955) Malignant change arising in tissues affected by herpes. BMJ 2: $1106-1109$ 